UDC: $811.134 .1 ' 282$

DOI: https://doi.org/10.18485/beoiber.2018.2.1.12

Josep Vidal Arráez ${ }^{1}$

Université de Toulouse 2 Jean Jaurès

France

\title{
CREACIÓ I IMPLEMENTACIÓ D’UNA UNITAT DIDÀCTICA DE LLENGUA, CULTURA I LITERATURA CATALANES A LA UNIVERSITAT DE TOLOSA
}

\begin{abstract}
Resum
Aquest article descriu el procés de concepció i realització d'una unitat didàctica singular que permet posar en pràctica tots els coneixements adquirits pels estudiants, durant l'any, gràcies a un seguit de materials culturals. Aquesta experiència té lloc, cada any, a la Université de Toulouse Jean Jaurès, en el marc de les classes de català per a especialistes d'altres disciplines (LANSAD).

El punt de partida és la Diada de Sant Jordi, jornada representativa de la tradició i de la cultura catalanes $\mathrm{i}$ en la qual l'obra literària juga un paper eminent. Aquesta importància del llibre és una ocasió única per introduir, dins dels diversos nivells de LANSAD de català, l'obra i la figura de diferents escriptors catalans actuals, preferentment polièdrics i complexos i que treballin diferents gèneres literaris. La tria d'un autor encara viu ens permet ressaltar el caràcter actual de la literatura als nostres estudiants.

Aquesta unitat didàctica es du a terme tenint en compte els coneixements previs dels nostres estudiants i sense perdre mai de vista els objectius pedagògics concrets de cada grup. Al final de la unitat, els estudiants, no tan sols hauran pogut descobrir nombrosos aspectes de les diverses obres i biografies de l'escriptor seleccionat sinó que a més, una trobada final amb l'autor els donarà l'oportunitat d'intercanviar amb ell totes aquelles hipòtesis i preguntes sorgides durant la unitat.
\end{abstract}

Paraules clau: Didàctica, català, cultura, llengua, literatura.

\section{DESIGN AND IMPLEMENTATION OF A LESSON PLAN OF THE CATALAN LANGUAGE, CULTURE AND LITERATURE AT THE UNIVERSITY OF TOULOUSE}

\begin{abstract}
This article describes the process of designing and implementing a unique four-week lesson plan that enables the students to put into practice all the knowledge acquired during the academic year, by using a series of cultural materials like videos, readings, etc. This experience takes place every year at the University of Toulouse Jean Jaurès, within the framework of Catalan language classes aimed at specialists from other disciplines (LANSAD).

\footnotetext{
${ }^{1}$ josepvidal.a@gmail.com
} 
The starting point is Sant Jordi's Day, a representative Catalan tradition and a culture date, in which literary works play an eminent role. The importance of books provides a unique opportunity to introduce to our various levels of LANSAD the work and the figure of different current Catalan writers, preferably polyhedral and complex authors, who represent several literary genres. The choice of an author still alive allows us to emphasize the contemporaneous nature of literature to our students.

This lesson plan is implemented taking into account previous student knowledge and upholding the specific pedagogical objectives of each group. At the end of the unit, students will have explored the biography and works of the selected writer. In addition, a final meeting with the author will give learners the opportunity to exchange with him or her all those hypotheses and questions that arose during the lessons.

Key words: didactics, Catalan, culture, language, literature.

\section{Introducció}

El fet que les classes de llengua acostumin a incorporar, dins del seu programa, aspectes $\mathrm{i}$ continguts culturals no és estrany ni és cap novetat. De fet és una pràctica abastament estesa sobretot en cursos de llengua per a nouvinguts com els que fa, a Catalunya, el Consorci per a la Normalització Lingüística. Aquesta pràctica permet que els estudiants adquireixin coneixements lingüístics i que, a més, surtin de l'aula amb variats coneixements culturals que els permetran, posteriorment, una millor comprensió de la realitat cultural i social en què viuen, fet que els ajudarà, segurament, a adaptar-se millor a la comunitat d'acollida.

Històricament, l'interès pel component cultural en l'aprenentatge de llengües estrangeres ve de lluny. Al segle XIX, per exemple, el mètode gramàtica-traducció treballava la llengua a través de la literatura, atès que la cultura estrangera era sinònim de literatura i de belles arts (Germain 1993: 103). Amb el pas del temps, i amb la successiva irrupció de noves tendències com el mètode directe o el mètode audio-oral, el concepte de cultura evolucionarà, paulatinament, englobant disciplines com ara la història o la geografia, i fins i tot, a partir dels anys 70 , diferents elements de la vida quotidiana.

Amb l'aparició de l'enfocament comunicatiu i del Marc europeu comú de referència per a les Llengües (MECRL), l'ensenyament de llengües estrangeres ha fet un pas més per emfasitzar de manera significativa l'aprenentatge dels aspectes socioculturals $\mathbf{i}$ sociolingüístics associats a la llengua i al país on aquesta es parla.

Ara bé, com s'integren els trets culturals, el patrimoni o bé les tradicions d'una determinada societat a les classes de llengua que no es duen a terme en el país on aquesta es parla? Com s'incorporen $\mathrm{i}$ es treballen aquests aspectes quan s'està a centenars de kilòmetres de distància? I encara més, què s'ha de fer per mostrar a l'alumnat que aquests fets culturals són reals i estan ben vius, i que tot plegat no és només una auca de records?

Aquestes i altres preguntes són les que ens vam formular a la secció de català de la Université de Toulouse 2 Jean Jaurès (UT2J), tot just començar el curs escolar 2014-2015, 
i que van incentivar la creació de la unitat didàctica que ara us presentarem i que encara duem a la pràctica avui dia.

\section{Context general}

Amb prop de trenta mil estudiants, la UT2J figura entre les millors universitats d'arts, llengües i ciències socials i humanes de França. A més, compta amb l'únic centre d'adquisició i de difusió d’informació científica i tècnica (CADIST) sobre llengua, literatura i història ibèrica i iberoamericana de França.

Fruit d'aquesta situació, i gràcies al treball iniciat ara fa 84 anys per Josep Sebastià Pons i continuat per Alfons Serra i Baldó, Michel Camprubí i el difunt Pere Gamisans, el català és una de les diverses llengües que s'estudien a la capital de la regió d'Occitània. Actualment, dirigits per Fabrice Corrons, els estudis de català a l'UT2J proposen una oferta formativa dividida en tres modalitats: la major, és a dir la llicenciatura de filologia catalana; la menor, l'equivalent dels minors de les universitats catalanes però iniciats des del primer any de carrera i, finalment, el català com a assignatura optativa. A més, totes tres modalitats es poden cursar de forma presencial o bé a distància.

Durant el curs 2016-2017, els nostres estudis van tenir un total de dos-cents dotze inscrits, una xifra gens menyspreable, i més tenint en compte les llengües amb què competim: l'alemany, l'anglès, l'àrab, el castellà, el xinès, el japonès, l'italià, l'occità, el portuguès i el rus. A més, cal afegir que la secció de català de l'UT2J també compta amb una docent a temps parcial i un lector de català, signant d'aquest article, finançat íntegrament per l'Institut Ramon Llull, institució pública encarregada de promoure l'ensenyament de la llengua, la literatura i la cultura catalanes fora del domini lingüístic català.

\section{Reptes a superar}

Durant el quinquenni 2010-2015, i malgrat la inscripció, de manera regular, de prop d'un centenar d'estudiants als cursos de català, la vitalitat dels nostres estudis a l'UT2J no semblava pas assegurada. La nostra realitat reflectia un gran nombre d'inscrits a principis d'any que ràpidament minvava per culpa, principalment, de dos factors: d'una banda, la possibilitat d'anular la matrícula després d'haver "tastat" algunes classes i, de l'altra, l'abandonament escolar a partir del final del primer semestre - malauradament, una pràctica molt habitual en el sistema universitari francès, finançat quasi al 100\% per l'Estat. A aquesta anquilosada crisi en el nombre d'inscrits entre el primer i el segon semestre cal sumar que a la tardor de l'any 2014 va morir el responsable de la secció de català, en Pere Gamisans. 
La mort, tot just començar l'any acadèmic, de la persona que durant 26 anys havia dirigit els estudis de català a l'UT2J va deixar la resta de l'equip pedagògic força trasbalsat i tocat però amb la imperiosa responsabilitat d'agafar les regnes de la secció i continuar endavant. En aquest sentit, l'equip pedagògic va saber reaccionar a temps i va aprofitar aquest dolorós moment per donar un cop de timó i mirar de redreçar el rumb dels nostres estudis.

Els principals reptes que calia afrontar ràpidament eren tres: en primer lloc, oferir uns estudis de català amb rigor pedagògic que, tanmateix, fossin atractius i engrescadors; en segon Iloc, establir una metodologia de treball en sintonia amb el nostre alumnat que els fes més propera i amena la nostra llengua, cultura i literatura, i, finalment, posar en relació els estudiants dels diferents nivells amb què comptava el català a la nostra universitat. Aquest darrer punt ens semblava força interessant, atès que, normalment, la majoria dels nostres estudiants no es coneixen entre ells i creuen ser els únics que estudien català, sobretot, en el cas dels estudiants de primer any.

En aquesta línia, aconseguir acostar el fet cultural català al nostre alumnat ens semblava i ens sembla cabdal, ja que a partir d'aquest es poden treballar diferents aspectes lingüístics, literaris $\mathrm{i}$ fins $\mathrm{i}$ tot sociològics de la nostra llengua i del nostre país. Tanmateix, no és sempre tan senzill. És per això que la secció va decidir treballar la cultura i tradició catalanes des d'un altre punt de vista: no enfocant-la de manera directa i específica sinó més aviat intentant que l'alumne arribés a interessar-s'hi, comprenent-la i compartint-la a través de la feina realitzada a classe, en el terreny lingüístic i literari.

\section{Marc teòric}

La unitat didàctica que presentem va ser concebuda com un intent d'explotar al màxim tot allò treballat durant l'any acadèmic per tots els nivells de llengua presents a la nostra universitat, des del nivell A1 fins al B2. Més endavant n'aclarirem els detalls i funcionament.

Els pilars pedagògics i educatius d'aquesta unitat provenen de dos models complementaris: el del MECRL i el del Groupe Français d'Education Nouvelle (GFEN). Si bé són dos models ben diferents, ambdós comparteixen, com a mínim, dues característiques: d'una banda, el fet de situar l'alumne al centre de l'acció educativa i, d'una altra, oferir a l'estudiant les eines apropiades perquè pugui resoldre amb solvència les diferents situacions socials comunicatives pròpies de la vida quotidiana.

Publicat l'any 2001, el MECRL és fruit de la feina feta pel Consell d'Europa en matèria lingüistica per tal de fomentar una Europa multicultural i plurilingüística. Instrument de planificació i harmonització de l'aprenentatge de llengües a Europa, el MECRL intenta donar una base comuna que serveixi a la creació de currículums i programes educatius així com a l'elaboració d'exàmens i certificats. En aquest sentit, "descriu d'una manera exhaustiva el que han d'aprendre a fer els aprenents de llengua per 
utilitzar una llengua per a la comunicació, i els coneixements i habilitats que han de desenvolupar per ser capaços d'actuar de manera efectiva" (MECRL 2003: 19).

Tanmateix, les principals aportacions del MECRL creiem que són, d'una banda, la de concebre per primera vegada l'estudiant de llengües com un "agent social" implicat en la societat i la cultura de la llengua que estudia i, d'una altra, el fet de proporcionar tot un reguitzell de temes i àmbits d'actuació a treballar per tal d'ajudar-lo en el seu aprenentatge. Ara bé, si l'estudiant vol esdevenir aquest "agent social" li caldrà posar en pràctica totes les seves habilitats i competències personals, ja siguin lingüístiques com culturals. Per arribar a ser un "agent social" competent, el MECRL considera que cal que l'estudiant sigui capaç de superar els diferents límits i exigències implicats en una situació comunicativa. És per aquest motiu que el Consell d'Europa aconsella treballar a partir de tasques pedagògiques que l'estudiant haurà d'acomplir. Segons el MERCL, "una tasca és qualsevol acció intencionada que una persona considera necessària per aconseguir un resultat concret en el context d'un problema a resoldre, una obligació a complir o un objectiu a assolir" (MECRL 2003: 28). Així doncs, perseguint l'objectiu final de transformar l'estudiant en un "agent social", el document privilegia una perspectiva orientada a l'acció, la qual, al seu torn, mobilitzarà l'activació d'un seguit de competències i estratègies lingüístiques i cognitives, inherents à l'estudiant, que li permetran resoldre el repte proposat de manera satisfactòria.

Per la seva banda, el GFEN parteix de la base que el saber no és una cosa que es transmet sinó que es construeix. En aquest sentit, aquest nou corrent pedagògic mira de proporcionar al professorat recursos específics perquè els estudiants siguin, per si mateixos, els qui creïn aquest saber (Fusté 2015). Es tracta, doncs, de generar situacions d'aprenentatge en les quals els estudiants siguin actors principals de l'acció. En aquestes situacions, els estudiants s'hauran d'enfrontar a diferents activitats, tasques i obstacles que els permetran avançar a mesura que es vagin superant, mentre construeixen el saber necessari. La pedagogia GFEN promou una construcció del saber en diferents etapes: una primera d'individual, en la qual cada estudiant aporta la seva experiència i coneixement de la qüestió a treballar; una segona fase on es comparteix en petit comitè aquesta experiència i coneixement personal per tal de valoritzar-la i veure si hi ha coincidències en el grup i, finalment, una tercera fase, aquest cop grupal, en la qual cada grup explica als companys la seva versió dels fets i on mitjançant aquesta posada en comú es construeix un saber final compartit fruit de la reflexió i del treball de tots els estudiants, a partir dels seus coneixements anteriors i actuals.

\section{Metodologia}

Per crear la nostra unitat didàctica, com acabem d'apuntar, ens vam basar tant en l'enfocament per tasques del MERC com en l'auto-socio-construcció del saber que 
proposa el GFEN, en matèria d'ensenyament de llengües. ${ }^{2}$ Com a resultat de la combinació d'ambdós models, la figura del docent que imparteix classes magistrals es transforma per donar pas a la del docent que condueix i orienta l'alumne vers el seu propi aprenentatge. D'aquesta manera, s'emfasitza la construcció del saber per part dels estudiants i es defuig la idea tradicional que el coneixement ha de ser transmès exclusivament per la figura del professor.

Els principals objectius de la unitat didàctica creada originàriament el 2014 - i encara practicada avui dia - eren: d'una banda, fer descobrir als alumnes la figura d'un jove i polifacètic escriptor català actual - el vigatà Gerard Guix - i, de l'altra, construir un seguit de materials que ens permetessin, l'últim dia de curs, fer una presentació acurada de l'autor en la seva presència. ${ }^{3}$ La tria d'aquest autor va respondre, entre d'altres, a factors conjunturals com ara el fet que el responsable de la secció de català de la nostra universitat sigui especialista en literatura actual, i en particular en la producció d'aquest autor, així com també al fet que les seves traductores oficials franceses siguin també professores a la nostra facultat. Ara bé, aquesta unitat didàctica es fàcilment transposable a qualsevol altre escriptor dels Països Catalans, com bé hem fet nosaltres mateixos des d'aleshores.

No obstant això, aquesta unitat també tenia altres objectius secundaris però no per això menys importants, a saber: un repàs dels coneixements i estructures ja apreses així com el reforç dels usos lingüístics adquirits; l'aprenentatge i consolidació del lèxic específic sobre els temes a tractar; la progressió en les diferents competències lingüístiques, etc.

El punt de partida va ser l'avinentesa de la Diada de Sant Jordi 2015 i el fet que el grup d'estudiants d'A2 ja haguessin treballat, l'any anterior, la llegenda del Sant així com la festa literària que se celebra el 23 d'abril al nostre país. Aquesta conjuntura va motivarnos a voler anar un xic més enllà i treballar de manera més específica l'aspecte literari de la jornada, proposant el següent tema: la descoberta d'un autor, la literatura com a tema cultural. A partir d'aquesta decisió, vam mirar de crear una unitat didàctica que ens permetés abordar un mateix autor però des de diferents punts de vista i que tingués en compte a tots els nivells de català presents a la universitat.

La metodologia emprada es va basar en la proposta didàctica del MECRL, és a dir, en què els estudiants fessin petites activitats que possibilitessin, a posteriori, la resolució d'una tasca final més complexa. Aquestes activitats permetien que els alumnes treballessin amb i en diferents formats - tant orals com escrits - de manera autònoma o grupal, tot

2 Per manca d'espai no hem pogut desenvolupar, de manera més extensa, els fonaments teòrics del MERCL ni del GFEN. Per saber-ne més, el lector pot consultar els següents enllaços:

http://llengua.gencat.cat/ca/serveis/informacio_i_difusio/publicacions en linia/classific temes/temes materia Is_didactics/marc_europeu_de_referencia_per_a_les_llengues; http://www.gfen.asso.fr/fr/accueil.

${ }^{3} \mathrm{Val}$ a dir que aquest darrer apunt no es va desvetllar fins l'última sessió per no condicionar el treball de l'alumnat. Cal afegir, a més, que la celebració de la Diada de Sant Jordi coincideix amb l'última setmana del curs lectiu de la universitat, motiu pel qual, la trobada amb l'autor serveix de colofó de l'any acadèmic. 
interactuant entre ells. Es partia, doncs, de l'enfocament per tasques que promou el treball de la comprensió i expressió oral i escrita. D’altra banda, també es fomentava que fossin els propis estudiants els qui creessin i construïssin el seu propi saber, com estableix el GFEN. Per tant, el professor només va proporcionar les eines necessàries per a la construcció del coneixement alhora que de manera presencial va conduir, assessorar i orientar els diferents grups de treball.

En aquest sentit, tant a l'inici com durant les diferents activitats, el professor va repartir diversos materials i es va encarregar de donar consignes clares i precises als alumnes per tal que aquests poguessin acomplir les tasques encomanades. ${ }^{4}$ Al llarg de la unitat es va exposar tot el material a l'aula perquè servís de referent i suport a l'aprenentatge. De la mateixa manera, el material elaborat també es va penjar al campus virtual de l'assignatura.

La unitat didàctica, estructurada en quatre sessions de dues hores de durada cadascuna, ${ }^{5}$ va comptar amb la participació de tots els estudiants presencials de català, concretament vuitanta-vuit alumnes. Cada nivell va treballar pel seu compte durant tres sessions i només es van trobar tots junts en la darrera. Des del primer dia ja es va anunciar als estudiants que, en la darrera sessió, caldria mostrar la feina efectuada a la resta de companys dels altres cursos i nivells.

El sistema d'avaluació es va basar en un sistema de control continu i tenia dos focus d'atenció: l'alumne i el mateix professor. L'avaluació de l'estudiant sorgeix de l'observació del treball fet a classe i a casa i ha de tenir sempre present en quin punt de l'activitat es troba aquest i què necessita. Evidentment, la producció i realització de l'última tasca de la unitat, així com l'examen final, tenen un pes important en l'avaluació de l'alumne. D'una altra banda, el professorat ha de ser valorat per la seva tasca d'observació i per la seva adaptació a les diferents reaccions, moments o actituds de l'alumnat, en els quals haurà d'ajudar-los a completar, amb succés, la tasca encomanada.

\section{Mise en place}

Com hem apuntat anteriorment, la unitat didàctica tenia dos objectius principals: descobrir el polifacètic escriptor català Gerard Guix i construir un seguit de materials que ens permetessin fer una presentació acurada de l'autor, en l'última sessió, coincidint amb l'últim dia de curs. Ara bé, la unitat contenia una sèrie de paràmetres desconeguts per a l'alumnat com ara el fet que l'autor seria present el dia de l'exposició final i que, tots ells, cadascú en el seu nivell, estaven treballant el mateix tema des d'òptiques i nivells diferents.

${ }^{4}$ El professor ha de revisar els materials produïts pels alumnes constantment perquè aquests puguin construir el seu coneixement sobre una base supervisada i correcta.

${ }^{5}$ Aquest fet no exclou la possibilitat que s'hagin de realitzar activitats complementàries a casa. 
La voluntat de treballar un mateix tema amb tots els estudiants és fruit de la reflexió i convicció que tothom és capaç, al seu nivell, de poder treballar, comprendre i aportar coneixement en relació a un tema concret. Val a dir, a més, que aquest enfocament ens permetia concentrar-nos de manera puntual en cada un dels grups i fer aflorar totes les habilitats i competències específiques, adquirides en cada nivell, alhora que treballàvem un seguit de punts claus i concrets de l'autor a estudiar.

La conjuminació d'aquestes dues idees comporta l'abast total del tema triat, atès que cada grup disposa d'una informació específica i concreta de l'autor, desconeguda per tots els altres companys. Així doncs, cada grup és el posseïdor d'una part del coneixement i només amb la compartició grupal d'aquest és com s'arribarà a tenir el coneixement complet del tema en qüestió.

A partir d'aquest enfocament, cada grup d'estudiants es va ocupar d'una o diverses parts del tot, a saber:

a) Nivell A1:

a. Descobriment de la llegenda de Sant Jordi i de la Diada del 23 d'abril.

b. Reflexió i definició - individual i grupal - sobre què és, com és i/o com hauria de ser un escriptor. Es treballa lèxic específic alhora que es reforcen les estructures apreses per manifestar hipòtesis.

c. Descobriment de l'escriptor Gerard Guix i el seu univers mitjançant extractes de la seva obra, vídeos i entrevistes. Posteriorment, elaboració d'un resum de la seva biografia.

d. Descripció de l'autor a partir de diferents fotografies actuals i de quan era infant. Elaboració de dos textos descriptius en els quals l'alumnat explica com ha canviat l'autor $\mathrm{i}$ on estableixen un seguit d'hipòtesis sobre el seu caràcter, temperament, gustos i costums en base a tot allò vist durant la unitat.

e. Redacció de totes aquelles preguntes que li faríem a un escriptor si en tinguéssim l'oportunitat.

b) Nivell A2:

a. Descobriment de l'obra El cementiri a partir de documents visuals i sonors. Sobre quin tema tracta? Posada en comú. Formulació d'hipòtesis argumentades. Descripció d'allò visionat.

b. Creació d'un breu text narratiu a partir de les diverses il-lustracions que conté l'obra El cementiri i a partir dels visionats anteriors. Sense conèixer l'ordre real de les imatges dins del text, els estudiants han de ser capaços de generar i crear una història pròpia, a mode de resum del llibre. Posada en comú de les diferents històries $\mathrm{i}$ valoració dels aspectes compartits i de les divergències entre els grups.

c. Treball sobre els referents literaris, iconogràfics i simbòlics de l'autor a partir d'un document creat per ell mateix. Qui o què són? Què representen? Com això influeix, varia o modifica completament les vostres hipòtesis sobre l'obra 
d. Lectura de la primera pàgina de la novel-la. Reflexió individual i posteriorment en grup sobre el tema tractat. Visionat d'un segon vídeo relacionat amb la novel·la. Creació i/o modificació del nostre text narratiu.

c) Nivell B1:

a. Treball específic sobre les obsessions de l'autor a partir d'un document iconogràfic creat per ell mateix. Què els transmet? Com creuen que es pot veure traslladat a l'obra de l'autor? D'on creuen que pot sorgir? Quines influències ha rebut?

b. Formulació de preguntes en referència a l'univers simbòlic i d'inspiració de l'autor.

c. Descoberta de les obres La deriva dels continents i Tot el que hauries de saber abans d'estimar-me. Elaboració d'un resum de cadascuna.

d) Nivell B2:

a. Treball específic dels articles periodístics en revistes digitals com ara: Guess Who's Comming to Dinner. ${ }^{6}$ Anàlisi del gènere, del vocabulari, de la sintaxi i de l'estructura de l'article.

b. Elaboració d'un model d'entrevista basat en l'estructura que segueix l'escriptor Gerard Guix per entrevistar els seus convidats.

c. Guió de la posada en escena de tot el treball efectuat pels diferents grups.

e) Estudiants de Filologia catalana de primer i de segon any:

a. Treball sobre l'univers simbòlic i argumental de l'autor a partir de fotografies genèriques dels seus temes. Es treballa vocabulari específic, es formulen hipòtesis, es busquen acords $\mathrm{i}$ es donen arguments a fi d'establir quin és l'univers temàtic i simbòlic de l'escriptor.

b. Visionat de diversos videotrailers de l'obra de l'autor per tal de contrastar, reafirmar o modificar les idees suggerides anteriorment. Què defineix a priori l'obra de l'autor? Quins temes aborda?

c. Descoberta de la trilogia de Gerard Guix El Prodigi, L'Enginy i El Talent mitjançant retalls de premsa, la portada i la contraportada dels llibres, crítiques literàries i videotrailers. Cal elaborar-ne una síntesi i resum explicatiu.

d. Descoberta de les obres teatrals: U, due, três, Arca i Ricard de 3r. Elaboració d'una síntesi i resum.

e. Exercici de traducció de les primeres pàgines de la novel·la El cementiri, i posterior correcció d'aquest gràcies a la presència a classe de Carole Filière, traductora al francès d'aquesta obra.

${ }^{6}$ Més informació a: http://www.catorze.cat/grans/temes/540/guess/who/coming/to/dinner 
Així doncs i com es pot observar, cada grup tenia tot un seguit de temes i aspectes diferents a treballar, els quals, de manera conjunta, abastaven la vida i l'obra completa de l'autor.

En la tercera sessió de la unitat es va reservar una part de la classe per a fer una exposició i presentació oral de tot el material elaborat, de cara a preparar l'exposició final davant dels altres companys. Aquest exercici permetia, d'una banda, avaluar la feina realitzada així com la producció oral de l'alumnat. A més a més, això els permetia preparar-se, sense que ells ho sabessin, per a la posterior exposició, ara sí, davant de l'escriptor.

En la quarta i darrera sessió, l'exposició de la feina feta davant del propi autor, és quan la tasca específica feta cada grup va adquirir tot el seu sentit. El fet que cada grup només conegués un aspecte de l'autor i que aquest fos desconegut pels altres grups, proporcionava, diguem-ne, un capital importantíssim per a cada nivell, ja que s'erigien en especialistes d'una faceta de l'escriptor i tenien la responsabilitat d'aportar el seu coneixement a la resta de companys. Aquest fet, lluny de generar por o inseguretat, va crear un ambient de serenor sabedors, tots ells, que coneixien la matèria i que en cas d'equivocar-se, d'una banda, els altres grups no se n'adonarien, i d'una altra, l'autor seria present per poder acabar de complimentar-ho.

Finalment, també cal posar en relleu la tasca duta a terme pel grup de B2 el qual va fer de director d'orquestra de la trobada. Gràcies al seu nivell més avançat de català, els estudiants de B2 van prendre el rol d'introductors i dinamitzadors de la jornada. Des d'un primer moment, la confiança d'aquest grup en les seves capacitats, aptituds i coneixements va transmetre una gran serenor a la resta de nivells. Després d'una breu introducció, els estudiants de B2 van anar introduint els diferents alumnes dels altres nivells, els quals, al seu torn, exposaven tant a en Gerard Guix com a la resta de companys el treball efectuat a classe. Poc a poc, tothom va dir-hi la seva sota l'atenta mirada d'en Gerard, el qual no s'esperava, ni de bon tros, que els alumnes tinguessin un coneixement tan aprofundit d'ell ni de la seva obra. Aprofitem l'avinentesa per agrair una vegada més a en Gerard Guix la gentilesa de voler participar en aquesta unitat "pilot", a ulls clucs i amb la premissa de no fer cap pregunta al respecte, deixant-se portar pels esdeveniments, així com els va succeir a la resta de participants a la trobada.

\section{Valoració final i conclusions}

La unitat didàctica va ser un èxit en tots els sentits. Pel que fa a la vessant didàctica i pedagògica, es van poder treballar i assolir tots els objectius marcats a priori. De fet, la posada en escena de l'últim dia va constatar fins a quin punt els diferents aspectes vistos a l'aula havien quedat clars i s'havien adquirit amb escreix. Així doncs, es complia amb el 
repte d'engegar una nova metodologia de treball amb rigor pedagògic que resultés atractiva i engrescadora.

Així mateix, també es va assolir la fita d'aconseguir apropar la llengua, la literatura i la cultura catalanes al nostre alumnat de forma divertida i amena. Sincerament, com a professor és molt gratificant veure treballar l'alumnat de manera autònoma i interessada en la matèria proposada. No sempre és fàcil motivar els estudiants vers els temes a treballar durant el curs. En aquest sentit, va ser sorprenent l'interès mostrat per l'alumnat quant a l'escriptor escollit i la seva obra. Val a dir que el fet que en Gerard Guix sigui força jove i que tingui una obra literària principalment dedicada als adolescents, també va ajudar i força a la motivació extra dels alumnes.

Finalment, i de manera molt important des del punt de vista intern, també vam aconseguir que es coneguessin, entre ells, tots els estudiants de català de la nostra universitat. Per una llengua com el català, en una universitat com la nostra, és molt important donar-se a conèixer i mostrar als qui l'estudien, que no estan sols, que no són els únics, que la llengua és viva i que tenen amb qui compartir-la. Des d'aquest punt de vista, el repte es va veure superat i amb un èxit inesperat, atès que la trobada va generar tot un seguit de trobades entre els estudiants que han donat lloc a noves amistats, intercanvis lingüístics, etc.

La descoberta del coneixement de manera auto-socio-constructiva a través de l'aprenentatge per tasques és una fórmula màgica, simple i dinàmica d'adquirir competències i habilitats cognitives. El fet d'aprendre sense imposició sinó en base al propi coneixement o creació aporta un estímul molt valuós a l'alumne. D’aquest manera, els estudiants es veuen capacitats i encoratjats per arribar molt més lluny. Aquest fet propicia que els alumnes es facin seu el projecte pedagògic, s'hi sentin identificats i que creguin en les seves possibilitats d'arribar molt més lluny en la seva adquisició del saber. Una adquisició del saber que al ser posada en pràctica no deixa lloc als dubtes i posa de manifest les grans potencialitats d'aquest model educatiu.

\section{BIBLIOGRAFIA}

Consell d'Europa. Common european framework for languages: learning, teaching, assessment. Estrasburg: Consell d'Europa, 2001. (Traducció catalana: Marc europeu comú de referència per a les llengües: aprendre, ensenyar, avaluar. Barcelona: Generalitat de Catalunya, Govern d'Andorra i Govern de les Illes Balears, 2003). Web. 27 Gen. 2017.

Fusté, Roger. "Que peut-on apprendre du GFEN?". Journée d'études Quelles innovations pedagògiques pour l'apprentissage des langues? Lille, 27/03/2015. Inédito.

Germain, Claude. Évolution de l'enseignement des langues: 5000 ans d'histoire. Paris: CLE International, 1993. Impreso. 
Guix, Gerard. La deriva dels continents. Barcelona: Angle Editorial, 2005. Impreso.

-. Tot el que hauries de saber abans d'estimar-me. Barcelona: Columna Edicions, 2011. Impreso.

-. El Prodigi. Barcelona: Estrella Polar, 2011. Impreso.

-. L'Enginy. Barcelona: Estrella Polar, 2011. Impreso.

-. El Talent. Barcelona: Estrella Polar, 2012. Impreso.

-. El cementiri. Barcelona: Columna Edicions, 2013. Impreso.

Fecha de recepción: 14 de enero de 2018. Fecha de aceptación: 12 de abril de 2018. 